\title{
Social work perceptions and identity: How social workers perceive public and professional attitudes towards their vocation and discipline
}

Elizabeth Hobbs and Nikki Evans University of Canterbury, New Zealand

\begin{abstract}
INTRODUCTION: A century after Abraham Flexner's (1915/2001) infamous speech conveyed his "dismissive attitude toward social work's professionalism," Gelman and González (2016) reflected that social work is again at a critical juncture. The fight for recognition of social work's professional status has been influenced by multiple factors including negative public perceptions of the occupation. In Aotearoa New Zealand, professionalisation campaigns have been far from unifying, with diverse ideas about practice standards and accountability polarising opinions. At a time that the country is grappling with mandatory registration of social workers, this research considers the ways in which social workers perceive themselves, and the profession that they identify with.
\end{abstract}

METHODS: Semi-structured interviews with 83 social workers in Aotearoa New Zealand were conducted. Participants were required to be eligible for social work registration. Interview transcripts were thematically analysed.

FINDINGS: Several identity themes emerged during the analysis of the 83 interviews. The first theme relates to the ways in which statutory child protection social work has impacted on identity. The second, and perhaps predictable theme, is that many social workers in this study experienced significant professional marginalisation from their colleagues. The third theme emerged from participants' views about the likelihood of mandatory registration of social workers impacting on their identity and the professional standing of social work.

CONCLUSION: Most participants in the current study believed that mandatory social worker registration may positively influence the public's view of social workers, other professionals, and also social workers themselves. However, many participants seemed to experience levels of self-stigma - and potentially believe they are viewed more negatively by the public than they actually are. Social workers' perceptions of their role and profession is an area that warrants further investigation.

KEYWORDS: statutory social work; child protection; identity; registration; multi-disciplinary teams; public perceptions
AOTEAROA

NEW ZEALAND SOCIAL WORK 29(4), 19-31.

CORRESPONDENCE TO: Elizabeth Hobbs bethkhobbs@gmail.com 


\section{Introduction}

While the title "social worker" is likely to be familiar to many people, an understanding of exactly what a social worker does, or is, might be somewhat more elusive. Contrary to lay conceptualisations of social work that involve having cups of tea with people, filling in forms, and generally "helping people," the title social worker is a signifier that denotes both a vocation and an academic discipline.

Indeed, the global definition of the social work profession that was approved by the International Federation of Social Workers (IFSW) in July 2014, states that "[s]ocial work is a practice-based profession and an academic discipline" (para. 1). However, some research suggests that views of social work as a profession, and evaluations by social workers themselves of their profession, continue to be largely negative (Jordan, 2004; Leigh, 2016).

This paper reports findings from a study that looked at social workers' own perceptions of professional identity. Identity is acknowledged to a be fluid construct, and it is expected that social workers will come to experience, engage in, and execute their identities in different ways. However, the study of identity per se is not the sole focus of this paper. Within this paper, participants' beliefs about how their profession is perceived by the general public, how the participants viewed their own professional identity, and that of other social workers, are also explored. The following literature review presents current literature on this topic, and establishes the context for this research.

\section{Literature review}

Regardless of their role, or employing organisation, social workers often experience stigma and discrimination from the public, other allied professionals, each other, and sometimes from the people they are striving to help (Jordan, 2004; LeCroy \& Stinson,
2004; Leigh, 2016). Stigma and discrimination towards social workers can be subtle, such as the side-lining of social workers' knowledge and skills by allied health professionals within inter-disciplinary team contexts. Overt stigmatisation of social workers can occur when social workers are marginalised by their association with the vulnerable client groups they work with. Public perceptions that social work is primarily concerned with uplifting vulnerable children can also lead to clients de-valuing, and therefore underrating, the skills and knowledge of contemporary social workers.

\section{Circulation of negative messages}

There is an anecdotal, long-standing, stereotypical public view that social workers only work in the capacity of child protection in which their main role is to remove children from at-risk families to ensure their safety (Jordan, 2004). Although there is little research that specifically focuses on this issue, some research suggests that much of the negative reputation of social work as a profession is a result of media coverage of child abuse cases. This stems back to the 1980s where national and international scandals within child protection services, and accusations of poor practice were first widely publicised. The negative publicity of a number of devastating child deaths has laid social work practice on a platter for the New Zealand public to scrutinise, and has significantly damaged social work reputation and credibility (LeCroy \& Stinson, 2004). Such coverage has also meant the efficacy of the social work profession has been publicly called in to question (Leigh, 2016). Jordan (2004, p. 7) observes that despite changes in social work education, training, globalisation, and increased professionalism over the years, social workers are still "mocked and attacked." Media reports have, at times, been inflammatory with social workers implicated in destroying families (Booker, 2009). Essentially, negative media portrayal of social work has contributed to a crisis of public trust (Beddoe, 2015). 


\section{The role of the state in the creation of statutory social work reputation}

Government is not a passive player in the construction of social work identity. Indeed, one author has argued that government should actively target the ongoing negative media attention, and be seen to be taking action to improve the standards of practice for social workers (Jordan, 2004). Despite recent developments, the long-standing reluctance of the New Zealand government to adopt mandatory registration for social workers has undoubtedly had an impact on the standing of the profession (Hunt, 2017). As Hunt (2016) notes, "[p]rofessionalisation is a term which can describe both an individual's socialisation process into the context of an occupation and also the process by which an occupational group aspires to professional status that is shared internally and recognised externally" (p. 15). A lack of mandatory, legislated, external, recognition frameworks has undoubtedly impacted on the status of social work in this country (Hunt, 2017).

Hunt (2017) and Nash (2009) argue that multiple factors, some internal and others external to social work, have contributed to delays in implementing mandatory registration of social workers in Aotearoa New Zealand. Regardless of the reasons for earlier delays, a concerted push for the mandatory statutory regulation of social workers in Aotearoa New Zealand has been made before parliament in 2017. Beddoe (2015) argues that a crisis of public trust in social workers combined with the state's obsession with risk and accountability processes has contributed to the most recent push for mandatory registration in Aotearoa New Zealand.

The pursuit of validation, in and of itself, is not without risk. Indeed, van Heugten (2011) argues that, "[s]eeking status in the eyes of 'the public', 'the state', or employers, overly exposes social workers to the dangers of accommodation and compliance" (p. 186). Whatever the implications of the introduction of voluntary registration, and with the latest development of mandatory registration, social work in this country is on the cusp of a monumental shift with many challenges (Hunt, 2017).

\section{Status amongst peers}

Health professionals who require registration under the Health Practitioners Competence Assurance (HPCA) Act, 2003, including doctors, occupational therapists, and nurses, often struggle to recognise social workers as equals. Within interdisciplinary contexts, then, social work voices can be silenced or overridden (Beddoe, 2015). Charged with working with some of the most vulnerable people in any population, social workers can find themselves fighting for acceptance and recognition of their professional role, while also advocating for their clients' needs.

A shift to mandatory registration may enhance recognition of the discipline (Beddoe, 2015; Hunt, 2017). Whether statutory regulation will provide opportunities for greater responsibility to utilise theory, encourage ethical practice, enhance standards for professional education and post-qualification professional development, as well as retention of social justice frameworks, is yet to be seen (Harington, 2006; Hunt, 2017; van Heugten, 2011).

\section{Construction of identity}

In the 1970s, Condie, Hanson, Lang, Moss, and Kane (1978) acknowledged the struggles of social workers in developing identity and image. These authors explored identity in relation to the construct of prestige, which they defined as "the relative value attached to a status or position, independent of the individual who occupies it" (p. 47). Earlier, Kadushin (1958) had argued that, while prestige is important to a social work identity, it is also important to the profession as a whole, and the clients with whom social workers engage. 
Owing to the stigmatisation referred to earlier (LeCroy \& Stinson, 2004) resulting from negative publicity about high profile statutory social work failings, and ongoing debate about registration of social workers (Hunt, 2017), the word prestige is unlikely to be used to describe the status or identity of social workers in this decade. Regardless of the terminology used to describe social work roles or tasks, historical perceptions of social work appear to be exceedingly negative. Condie et al. (1978) identified that almost all public respondents would be reluctant to seek support from a social worker for their personal concerns. Another more recent study revealed that appraisals of social workers from members of the public were predominantly negative (Zugazaga, Surette, Mendez, \& Otto, 2006). There is a distinct lack of contemporaneous research looking at how public and professional perceptions affect social workers' own descriptions of identity. The current research aims to add to this knowledge base by inviting participants to explore their ideas about identity.

\section{Here, and now: The impact of impending mandatory regulation on social workers' identity}

Perceptions of social work have been seen as bleak by some authors (Dennison, Poole, \& Qaquish, 2007), and these perceptions need to be explored within the New Zealand context.

Politicians are key players in the development of a professional social work identity (Barretta-Herman, 1993; Hunt, 2017). In Aotearoa New Zealand, politicians have been petitioned by many social workers and the social work profession to develop legislation to regulate the profession, protect the title of "social worker", and thus create an alliance between the state and profession. The passing of the Social Workers Registration Act, 2003 allowed for voluntary registration of social workers in Aotearoa New Zealand. Yet, several years later, a Social Work Registration Board (SWRB) of New Zealand survey in 2007 found that people had more confidence in counsellors and psychologists than in social workers (SWRB, 2011). Currently, the Social Workers Registration Legislation Bill, 2017 is progressing through the New Zealand parliament with the intention of amending the SWR Act, 2003. Changes to the legislation include a move to protect the use of the title "social worker", if not necessarily the social work role and tasks.

State support of social workers has been slow. As Jan Logie, New Zealand Green Party politician, stated following the first reading of the Social Workers Registration Legislation Bill “in 2015, 500 social workers working within what was then CYF were as yet unregistered. They were staff members who had the support of the State working within the State institution, but, again, there does seem to have been a lack of commitment in ensuring that they had the support to get qualified and registered" (Logie, 2017, para. 54).

\section{Public perceptions are not as bad as people think}

A study by Staniforth, Fouché, and Beddoe (2014) surveyed 386 members of the public to ascertain their perceptions of social work. Their study found that people believed social work should be more visible and more should be known about what specific tasks social workers do. Staniforth et al. (2014) also note a common perception that social workers needed to be more effective, and perhaps efficient, in carrying out their work - something that perhaps has been influenced by national media coverage of social work failings in high-profile cases. Of particular note from that study though, was the discovery that the public actually had a good awareness of what roles social workers played, and the qualifications they require to practise. This is an evolutionary shift from findings in previous decades, solely identifying social workers as child protection workers (LeCroy \& Stinson, 2004; Staniforth et al., 2014). However, the shift in public knowledge and perception 
may not be reflected in social workers' own identity perceptions. An exploration of social workers' contemporaneous perceptions of their own identity and worth, is something that this research brings to the professional identity discussion.

In more recent research, Staniforth, Deane, and Beddoe (2016) surveyed 403 social workers online to elicit their views about how they think that social workers are perceived by the public. These views were then compared with those of the 386 members of the public from Staniforth, Fouché, and Beddoe's 2014 study. Staniforth et al. (2016) found that members of the public actually perceived social work in a more positive light than social workers believe they do. In the 2014 study, members of the public were asked to suggest three words that define social workers; most often people said "helper," "meets specific need" or "children/youth help." This was compared to how social workers responded in the 2016 study, believing that the public viewed them as "Child, Youth and Family," "helping," and "steals/remove kids." Other negative comments social workers expected the public to use to describe them included "do gooders" and "interfering/busy body."

Earlier research by Davidson and King (2005) also supports the findings from Staniforth et al. (2016). Davidson and King (2005) discovered that twice as many people were likely to have positive views of social work than negative ones. The study further identified that people believed social workers receive "bad press" and felt that this was an unfair reflection of the work that is done by social workers. The participants felt this stemmed from the media fostering negative perceptions in society about social workers. Any internalised negative view could have significant implications for the development of social work professional identity.

It is possible that public perception of social work has become more positive over the decades, but also that social workers themselves are still under the impression they are viewed less than favourably. This may lead to self-stigmatising by social work students who receive messages from the media and other social workers that do not accurately reflect current public opinion (Staniforth et al., 2016). If self-stigma is a real and prevalent phenomenon, it is important that education and internship opportunities foster confidence and actively work to reduce self-stigma.

With little in-depth qualitative research capturing how social workers believe other professionals, clients, and the public perceive them, there is little discussion about these factors in relation to identity formation. While acknowledging that identity is complex and multi-faceted, the study reported here aimed to provide new insights into the phenomenon of professional identity.

\section{The study}

This paper describes findings from a study that was undertaken by a group of final-year social work students under the supervision of the second author. The project focused on aspects of social workers' sense of professional identity and their views on contemporary issues such as use of professional supervision, mandatory registration of social workers, ongoing professional development opportunities, the status of social work in multi-disciplinary teams, and so on. The registration of social workers in Aotearoa New Zealand is a contentious topic and one that many of the interviewees spoke about at length.

\section{Methodology}

In this qualitative study, an interpretive approach was taken which allowed researchers to inductively interpret and reflect on what the participants said about their work, the profession, and their identity. The ontological approach used enabled the social workers interviewed to provide their meanings and reality to questions around professional identity within the context 
of a semi-structured interview schedule. This research design allowed the authors of this paper to explore the ways in which attitudes towards social workers impact on the development and maintenance of professional identity (Liamputtong, 2013).

\section{Method}

\section{Participants}

Over 80 participants were interviewed in this research study. Almost half identified as male - a higher proportion than was anticipated given the perceptions of female dominance within the profession (Staniforth et al., 2014). Without a registry of qualified social workers to use as a baseline measurement, it is difficult to speculate about how representative these participants are of social workers in general. Participants were required to be eligible for social work registration to participate in the research. No incentive to participate was offered, and participation was voluntary.

\section{Ethical considerations}

The Social Workers Registration Board (2016) Code of Conduct and Practice guidelines were followed throughout the research, in conjunction with the ANZASW (2013) Code of Ethics. Ethics approval was obtained from the University of Canterbury's Human Ethics Committee. All identifiable data about participants' employment agencies was removed from any publication of the data.

\section{Procedure}

Participant recruitment was achieved through snowball and purposive sampling methods. While these methods do not allow the researchers to calculate the representativeness of the sample, they are an effective means of seeking participants from a specialist field, and when there is an absence of a sampling frame. In this study, recruitment letters and notices were circulated to social workers mainly employed within the Canterbury region.
Each responding participant was contacted by a social work student via email or phone to arrange a face-to-face interview time. Each student interviewed between 1 to 5 participants, depending on their location and availability. Participants read and signed a consent form, and had the option to withdraw from the study at any time. Participants were asked semistructured interview questions regarding the social work profession, social work identity, and contemporary issues and debates. Every interview was digitally recorded, and transcribed verbatim. Each student completed their own coding and analysis, and produced a report based on their findings. This paper is based on one such report by the primary author, and is co-authored with the second author who developed and supervised the research project.

\section{Data analysis}

Thematic analysis was employed to identify, analyse and describe re-occurring patterns throughout the data (Liamputtong, 2013). Initial ideas were noted and coding commenced by the primary author, recording interesting characteristics from across the entire data set. Data were collated for each code, and potential themes were identified. After all the data were gathered, themes and subthemes were reviewed and further refined, and content emerged during the analysis. Themes to emerge included:

(a) the challenges and hurdles of social work;

(b) the concept of social work identity;

(c) registration and mandatory registration;

(d) struggles when developing professional identity; (e) the realities of the field;

(f) common conceptions and misconceptions of social work; (g) the culture of employing organisations; and (h) the influence of technology and research on practice.

Due to word-limit constraints, excerpts from 23 of the 83 participant transcripts have been included in this paper, in relation to three themes. The excerpts included were selected to reflect and relate to the original 
research question and current literature to provide fresh perspectives about the topic (Vaismoradi, Turunen, \& Bondas, 2013).

\section{Limitations}

While the research produced some extremely rich narratives, some limitations were evident, including sample size. Participants were interviewed in a range of settings, and by different interviewers which will have impacted on the information elicited in various ways. No additional demographic information, such as age or ethnicity was captured, so the diversity of participants could not be ascertained.

Finally, it is important to note that the respondents were largely drawn from the Canterbury region, and most likely had some affiliation to, or association with, the university the interviewers were studying with. In which ways, and to what degree, the demographics of the sample impacted on the information provided is not able to be determined. While the findings from this study are not able to be generalised, or seen as representative of all social workers' experiences, there is no doubt that they will contribute significantly to an area that has been poorly researched.

\section{Findings and Discussion}

\section{Statutory shame}

The legacy of the social status of statutory child protection social work appeared to have ongoing influence on social workers' perceptions of themselves, and the social sanctioning of their work. This legacy appeared to provoke an element of shame within social workers' self-identities. It was not entirely clear whether participants in the current study held a sense of shame about any alignment to statutory child protection social work, or whether they were actively trying to distance themselves from this label. Further research is necessary to explore the construct of statutory child protection social work shame in a more nuanced manner.
Participants mentioned the reputation of the statutory child welfare agency, Child Youth and Family (CYF) as it was previously known, in their interviews. A significant proportion of respondents noted their perception that this agency's reputation continues to colour views of social work. As one participant put it:

Over the years, CYF has got a pretty bad name, we are still very much dealing with the legacy of that.

Other participants suggested that the reputation of statutory child protection social work in New Zealand caused a misrepresentation of their professional purpose, role and identity. One participant commented that:

When someone identifies me as a social worker ... they think I work for CYF and take children off people. And for some people that's their only acknowledgement of what social work is. There's no acknowledgement that social work exists in other services apart from CYF.

Another participant noted that these assumptions had even led to expressions of sympathy and pity from others:

When you say to people "I am a social worker", they go "Oh my God, that must be so hard. You must be working with children that have been taken away from their families." So, they immediately think the job is about child abuse, child neglect, child maltreatment and your job is to save children from poor parents.

These themes are consistent with Staniforth et al.'s (2016) study which found that social workers tend to believe the public define them as people "stealing" or "removing kids." In the current study, many participants reflected on the negative impact that statutory child protection social work has had on the reputation of the profession. This is summed up well in the following excerpt: 
I think that often social work gets tarred by the statutory social work brush ... which is of course not accurate and often linked to this idea of children being taken away, which is really unfortunate I think - both for them and the social workers.

A number of participants suggested that narrow constructions of social work have impacted on their ability to undertake their work in a more comprehensive and holistic manner. One participant noted:

So really the challenges and the struggles have been around authenticating social work. And helping shift some of the mind-sets of what social work has been because their experience of social work has been through CYF, so they think that is what social work is all about.

However, as Staniforth et. al. (2016) established, the child protection categorisation did not appear in the "top five" words that members of the public used to define social workers. The findings from the current study suggest that New Zealand social workers may believe they are viewed less favourably by the public than they actually are.

Since the interviews for this research were completed, the New Zealand government has rebranded its statutory social work agency from CYF, to Oranga Tamariki Ministry for Vulnerable Children. At the time of the interviews, participants involved in this study were aware of many of the changes that were to be rolled out under this umbrella. Reputation, and all that contributes to and is impacted by it, does not occur in a vacuum. Of course, workers can adopt or resist the socially constructed identity and status their employment provides (Leigh, 2016), but the inescapabilty of media representations of their identity is something they are less able to influence. Many participants talked about the role of the media in how their own social work identity is constructed.

\section{Media: Social work friend or foe}

In an article by former Chief Social Workers for CYF, Connolly and Doolan (2007) noted that "[i]n recent years, media and political focus on social worker error and calls for accountability and system reform have undermined the credibility and work of statutory child protection systems internationally" (p. 10). Consistent with the literature cited already, participants in this study considered the media to be heavily implicated in the communication of what social work is:

You go into social work and really trying to assist people to help themselves, which I think is not what the media portrays when they talk about CYF.

I think the biggest challenge facing social workers is other people's opinion or lack of understanding or judgements about what we do, whether that be in the media or like in a health setting.

Participants suggested that negative perceptions perpetuated in the media can prevent workers holding a positive professional identity. However, these negative portrayals have other insidious implications in relation to social workers' ability to perform their role, especially when they are engaging with families:

A lot of families who we go to see for the first time, think that social work is about taking kids into care. And historically, there is obviously a good reason for them thinking that. But quite often we are having to spend a lot of our initial engagement time explaining to people, look actually this is where we are coming from now, this is what our Act says, and ... what we are trying to do is to support young people in their families.

Another participant drew attention to the impact of this on the workers themselves:

I think that public perception is a pretty challenging thing for a lot of social 
workers, particularly these days. Social workers get a fairly hard time.

One participant stressed the need for the statutory child protection organisation to be more actively involved in changing its own reputation:

Working for CYF in itself, you are working for this juggernaut, which is approached with almost universal hatred by the population. Because whoever's doing the journalism for the publicity for CYF is doing an ABYSMAL job.

While more positive publicity was suggested as a way to restoring the public's faith in child protection services, one participant voiced another potential solution:

It's about educating people what social workers do because I think the profession's grown so much ... It's not just one specific thing, or ... just care and protection.

These narratives sit alongside the recent findings by Staniforth et al. (2014) who found that the public have a solid awareness of the functions and roles of social workers. Client experiences and perceptions are likely to differ from those of the general public as a whole, such as those reported by Staniforth et al. (2014).

The majority of people that social workers find themselves supporting have had previous social work involvement with services such as CYF. For all intents and purposes, social workers are exposed to a client group who hold a pre-determined view of social work. It is possible then, that social workers may internalise those views, and experience self-stigma as part of their identity. Future research examining social work clients' perceptions of social work, and social workers, may well mirror those of the social workers themselves.

As noted earlier, government is an active player in the construction of social work identity and has capacity to actively counter negative stereotypes or media attention (Jordan, 2004). Within statutory child protection contexts workers can, to a certain extent, adopt or resist the identity and status afforded to them via their employment. The process of a social worker "constructing and negotiating" their own professional identities involves grappling with agency-determined roles and tasks as well as the impacts of the professionalisation of their discipline (Leigh, 2016). Participants in this study were keenly aware of the potential for current changes to statutory child protection social work provision to impact on how social work is viewed in Aotearoa New Zealand.

\section{Professional marginalisation: Respect, value and professional identity}

The disparities between working for NGOs and government child protection or health agencies was a theme that emerged in this research, with social workers generally feeling more respected and valued in NGO settings. Many participants in the current study believed that social workers faced discrimination, marginalisation and oppression from other professionals they work alongside. Participants described secondary mental health services, where prominent power imbalances within their teams resulted in marginalisation of social workers and the social work role.

In a study of young children in statutory care in Aotearoa New Zealand, Connolly, de Hann, and Crawford (2014) emphasised the importance of cross-sector collaboration between health, maternal care, and child protection services as an essential component of positive outcomes for children. Despite broad acceptance of the benefits of cross-agency, and interdisciplinary collaborations, participants in this study frequently mentioned power differentials when working in interdisciplinary contexts: 
There is always an issue of power and the social workers don't have much power in a multidisciplinary team ... and they are probably a little bit marginalised in terms of their identity.

The de-valuing of social work interventions by other professionals was referred to by many participants in this study. This sometimes led participants to feel inclined to justify the complexity of their work. As one participant stated:

I think a lot of people don't know actually how hard social work actually is.

Participants identified how they feel they are silenced and how they perceive their knowledge, values, and skills are not appreciated:

I guess in some contexts it's having a voice, and having a valid voice. My experience [is that] the social work voice is not particularly well valued.

Within the context of marginalisation, professional status was mentioned regularly by participants. At times, an element of shame in being a social worker emerged from the narratives:

It's a profession that has really struggled over 30 years. It's had a low status. As a male, I have felt incredibly isolated ... So, when I'm introducing myself as a social worker, I almost feel like I need to add an apology.

Not always having a social work perspective valued, I think, is probably the biggest challenge sometimes, in a multi-disciplinary context ... we attribute different status to different professions, and social work doesn't have a great deal of status.

Beddoe's (2015) study of 40 social workers identified a constant fight for recognition by the social work profession, which mirrored an ongoing battle for social workers world-wide. Participants in the current study commented extensively on this issue. One participant suggested that the onus is on the social worker to prove themselves:

Coming into this agency you're working alongside psychologists, counsellors, psychotherapists in very clinical roles, and so the challenge was kind of separating ourselves from them as different, but still just as worthy.

Unequal pay continued to frustrate some social workers, and contribute to their sense that their occupation has a poor ranking in the professional field. The perception of professional marginalisation, and experience of social work occupying a lower status appeared to affect some participant's sense of worth:

I do get really, really annoyed that I don't get paid the same as my colleagues.

You feel like you are at the bottom of the heap, in hierarchical status and that is totally reflected in things like [salary] ...

A surprising and recurring sub-theme in the participants' narratives was the influence that psychologists have on social workers' identity and sense of value:

The last couple of years especially have been difficult in the team that I've been in ... having a great amount of difficulty for social work to be accepted. For example, I'll still have a colleague who says "oh, I don't know what a social worker does" and that's a psychologist.

The title of social worker doesn't buy credibility. In fact, I used to go out running with a guy who was a psychologist, and he reckoned that every social worker was a wannabe psychologist.

This was not the perspective of all social workers who participated in this research. A few described positive experiences which conflicted with the general consensus: 
I am aware that in some multi-disciplinary teams they're not valued, but we haven't really encountered it here at all.

I think our organisation is very supportive of our professional program ...they regard us as a flagship program and they value our profession[al] identity, they support it, they encourage it, they pay for it even in terms of paying membership of our professional association.

These findings show that while social workers may underestimate public perceptions of social work, many continue to experience a lack of recognition, value and respect from colleagues. The marginalisation that has been revealed by participants in this research suggests that one of the biggest impacts on social work identity for this group, may actually be the perceptions and behaviour towards social workers from other health professionals.

\section{Registration: Strengthening our identity and status}

The perception of public and professional scrutiny of social workers has had a significant effect on social workers' identity, with some avoiding the label entirely. Like the participant earlier who felt a need to identify with another profession for a period of time, another participant described identifying as a mental health worker to avoid potential perceptions of what a social worker is:

I [would] rather be called a mental health professional than a social worker, and I think that's because of my perception that people think social workers are pretty much a bunch of do good, tree hugging, jandal wearing, greenies.

Participants clearly spoke about how they thought mandatory registration may alter perceptions of social work:

I think overall it would be a good thing. Good for the public, good for the public perception of social workers and I'm pretty sure most other fields have it. You know registered psychologists, psychiatrists, yeah ... I acknowledge there's pros and cons but I think it's a good thing.

Everyone thinks social workers are flaky and we are just "do-gooders" and we are all talk and I think the compulsory registration is going to do a lot to help that. You know, it'll be a more professional kind of role.

Some noted a perception that voluntary registration had already impacted on their willingness to identify as a social worker, with one stating:

I think the social work identity in this country is definitely a lot better. I don't know if it is because of the establishment of the registration board or people are held more accountable. But, yeah, when I look at my identity, I'm quite proud to say that I am a social worker.

Most participants in this study believed mandatory registration would help their professional relationships and status, could improve professional and public perceptions, as well as confidence in social workers.

If you wanted to get your house built, some people look at it and think - oh this person is a member of the Master Builders Association so I can trust that the quality of their work will be a high standard. And I just see it as that ... we need to make sure that we are getting the right people that are doing it, we are getting people that are qualified and registered.

To some extent, I do support mandatory registration. I think it's good for the profession ... if it is a mandatory registered profession then we might have more professional authority because then not everybody can be a social worker. 
While not all social workers agreed that mandatory registration would be a positive step for social work as a profession, most strongly believed it would enhance their status and credibility, thus strengthening their professional identity. Despite the individualistic focus of registration and potential limitations of this framework (Beddoe, 2015; Hunt, 2017; van Heugten, 2011), participants in this study continued to explore the complexities and contexts of professional identity:

I'm very strong in identity - not just professional identity, personal identity as well. Actually knowing who you are, and where you come from and who you are here representing.

The idea that social work identity is not a singular, or static construct was also discussed, with one participant stating:

Even if I was 60 years into the profession, I hope that I'll still be working on who I am as a social worker.

\section{Conclusion}

This research uncovered perceptions held by social workers in relation to their views of public and professional attitudes to the social work profession and social workers.

A valuable insight gained was the finding that social workers appear to experience a level of self-stigma - and potentially believe they are viewed more negatively by the public than they might actually be. Another interesting finding was the phenomenon of professional marginalisation that transpired from the narratives, particularly in relation to other health professions and also specifically to the discipline of psychology. The sense of shame and feelings of professional insignificance that were deduced from the narratives for as many as two thirds of participants, were concerning.

However, there is a strong hope within the group interviewed that mandatory social worker registration may positively influence how social workers are viewed by the public, other professionals and also by social workers themselves. It could be useful for future research to explore the concept of selfstigma following mandatory registration for social workers in New Zealand, and whether the perception of the level of public scrutiny and professional marginalisation decreases. Social workers commit to a life-time of work empowering others and promoting equal rights for all people. It is ironic then, that as a profession, social work still needs to fight for recognition, acceptance, and a sense of belonging within the professional realm.

\section{References}

Aotearoa New Zealand Association of Social Workers (ANZASW). (2013). Code of ethics. Dunedin, New Zealand: Author.

Beddoe, L. (2015). Continuing education, registration and professional identity in New Zealand social work. International Social Work, 58(1), 165-174. doi:10.1177/0020872812473139

Barretta-Herman, A. (1993). Development of social work in New Zealand: 1969-1988. Part II: Social work professionalism. Social Work Review, 5(5), 30-35.

Booker, C. (2009). "Evil destruction" of a happy family. The Telegraph. Retrieved from http://www.telegraph. co.uk/comment/columnists/christopherbooker/5858902/ Evil-destruction-of-a-happy-family.html

Condie, C. D., Hanson, J. A., Lang, N. E., Moss, D. K., \& Kane, R. A. (1978). How the public views social work. Social Work, 23(1), 47-53.

Connolly, M., de Haan, I., \& Crawford, J. (2014). Focus on stability: A cohort of young children in statutory care in Aotearoa New Zealand. International Social Work, 6O(1), 111-125. doi:10.1177/0020872814554855

Connolly, M., \& Doolan, M. (2007). Responding to the deaths of children known to child protection agencies. Social Policy Journal of New Zealand, 30, 1-11.

Davidson, S., \& King, S. (2005). Public knowledge of and attitudes to social work in Scotland. Edinburgh, Scotland: Scottish Executive Social Research.

Dennison, S. T., Poole, J., \& Qaquish, B. (2007). Students' perceptions of social work: Implications for strengthening the image of social work among college students. Social Work, 52(4), 350-360.

Flexner, A. (1915/2001). Is social work a profession? Research on Social Work Practice, 11(2), 152-165. doi:10.1177/104973150101100202

Gelman, C. R., \& González, M. J. (2016). Reconsidering social work 100 years post-Flexner: Where are we now, where are we headed, what has been gained, what has been lost? Journal of Social Work Education, 52(sup1), S1-S5. doi:10.1080/10437797.2016.1192932

Harington, P. (2006). Practitioner scholarship and civic literacy: Will registration lift the game? Social Work Review, 18, 90-99. 
Hunt, S. (2016). The social work professionalization project before the 1990s in Aotearoa New Zealand: The dream. Aotearoa New Zealand Social Work, 28(3), 15-25. doi:http://dx.doi.org/10.11157/anzswj-vol28iss3id245

Hunt, S. (2017). The social work regulation project in Aotearoa New Zealand. Aotearoa New Zealand Social Work, 29(1), 53-64. doi:http://dx.doi.org/10.11157/ anzswj-vol29iss1id370

International Federation of Social Workers. (2014). Global definition of social work. Retrieved from http://ifsw.org/ policies/definition-of-social-work/

Jordan, B. (2004). Emancipatory social work? Opportunity or oxymoron. The British Journal of Social Work, 34(1), 5-19.

Kadushin, A. (1958). Prestige of social work-Facts and factors. Social Work, 3(2), 37-43.

LeCroy, C. W., \& Stinson, E. L. (2004). The public's perception of social work: Is it what we think it is? Social Work, 49(2), 164-174. doi:10.1093/sw/49.2.164

Leigh, J. (2016). The story of the PPO queen: The development and acceptance of a spoiled identity in child protection social work. Child \& Family Social Work, 21(4), 412-420. doi:10.1111/cfs.12157

Liamputtong, P. (2013). Qualitative research methods (4th ed.). Victoria, Australia: Oxford University Press.

Logie, J. (2017, Aug 17). Social Workers Registration Legislation Bill - First Reading. Retrieved from https://www.parliament.nz/en/pb/hansard-debates/rhr/ combined/HansDeb_20170817_20170817_32

Nash, M. (2009). Histories of the social work profession. In M. Connolly \& L. Harms (Eds.), Social work. Context and practice (2nd ed., pp. 363-377). Melbourne, Australia: Oxford University Press.

Social Workers Registration Board. (2011). Omnibus survey. Unpublished.

Social Workers Registration Board. (2016). Code of conduct and practice. Wellington, New Zealand: Author.

Staniforth, B., Deane, K. L., \& Beddoe, L. (2016). Comparing public perceptions of social work and social workers' expectations of the public view. Aotearoa New Zealand Social Work, 28(1), 13-24.

Staniforth, B., Fouché, C., \& Beddoe, L. (2014). Public perception of social work and social workers in Aotearoa New Zealand. Aotearoa New Zealand Social Work, 26(2/3), 48-60.

Vaismoradi, M., Turunen, H., \& Bondas, T. (2013). Content analysis and thematic analysis: Implications for conducting a qualitative descriptive study. Nursing \& Health Sciences, 15(3), 398-405. doi:10.1111/nhs.12048

van Heugten, K. (2011). Registration and social work education: A golden opportunity or a Trojan horse? Journal of Social Work, 11(2), 174-190. doi:10.1177/1468017310386695

Zugazaga, C. B., Surette, R. B., Mendez, M., \& Otto, C. W. (2006). Social worker perceptions of the portrayal of the profession in the news and entertainment media: An exploratory study. Journal of Social Work Education, 42(3), 621-636. 